\title{
CTNNB1 Gene Mutation
}

National Cancer Institute

\section{Source}

National Cancer Institute. CTNNB1 Gene Mutation. NCI Thesaurus. Code C36659.

A change in the nucleotide sequence of the CTNNB1 gene. 